\title{
Mechanical and flammability properties of poly(lactic acid)/ poly(butylene adipate-co-terephthalate) blends and nanocomposites: Effects of compatibilizer and graphene
}

\author{
Nilesh Kumar Shrivastava ${ }^{a}$, Ooi Shu Wooi a , Azman Hassan ${ }^{a, ~ *}$, Ibrahim Mohammed Inuwa ${ }^{b}$ \\ a Department of Bioprocess and Polymer Engineering, School of Chemical Engineering, Universiti Teknologi Malaysia, 81310 Skudai UTM, Johor, \\ Malaysia \\ b Department of Industrial Chemistry, Kaduna State University, Kaduna, Nigeria
}

* Corresponding author: azmanh@cheme.utm.my

Article history

Submitted 2 July 2018

Revised 2 August 2018

Accepted 23 October 2018

Published Online 3 December 2018

\section{Graphical abstract}

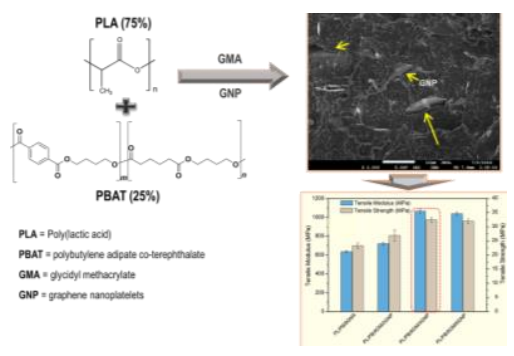

\begin{abstract}
Poly(lactic acid) (PLA)/polybutylene adipate co-terephthalate (PBAT) blends were prepared by melt blending and compatibilized by glycidyl methacrylate (GMA). The effect of graphene nanoplatelets (GNP) on these compatibilized blends were investigated by incorporating GNP at different content. The formulated blend and nanocomposites were characterized for mechanical, morphological, thermal and flammability properties by using universal testing machine, impact tester, field emission scanning electron microscope (FESEM), x-ray diffraction (XRD), Fourier transform infrared spectroscopy (FTIR), thermogravimetric analysis (TGA), limiting oxygen index (LOI) and UL-94 respectively. The incorporation of $8 \mathrm{phr}$ GMA into PLA/PBAT (75:25) blend as a compatibilizer results in a significant increase in impact strength (more than 14 times higher) compared to the uncompatibilized blend. Young's modulus and tensile strength of compatibilized PLA/PBAT nanocomposites increased upon addition of GNP and reached maximum values at $4 \mathrm{phr}$ before decreasing slightly. However, impact strength decreased with increasing GNP contents. The thermal stability and the flame retardancy of the GNP reinforced blend nanocomposites were also improved with an increase in nanofiller content and the maximum values for the nanocomposites were achieved at 6 phr. Interestingly, the nanocomposites samples showed a UL-94 rating of V0 at 4 and 6 phr of GNP. Morphological studies using FESEM showed the GNP were evenly distributed and dispersed in the PLA/PBAT nanocomposites. The current methodology to prepare PLA/PBAT blend nanocomposite is an economical way to produce high strength biodegradable polymer which also has good flame retardancy.
\end{abstract}

Keywords: PLA/PBAT blend, nanocomposites, graphene nanoplatelets, flammability, mechanical properties

\section{INTRODUCTION}

Poly (lactic acid) (PLA) is a bio-based and a biodegradable polymer which has attracted interest from academics and industrialist. In recent years, polymers from renewable resources have received much attention due to two major reasons; environmental concerns and the realization of limited petroleum resources. PLA has good mechanical properties and optical clarity. However, PLA is brittle in nature with a low elongation at break, poor melt strength, and low thermal stability $[1,2]$. Many studies have been reported to overcome the brittleness of PLA $[2,3]$. One of the ways to improve the ductility of PLA is through the incorporation of other polymers such as poly (butylene adipate-coterephthalate) (PBAT) $[4,5]$. PBAT is a biodegradable aliphaticaromatic polyester but not a bio-based polymer with the advantage of higher toughness and flexibility compared to PLA [6, 7].

In view of PBAT's high toughness and biodegradability, it is a promising candidate for toughening of PLA. Jiang et al. reported that the impact strength of PLA/PBAT blends dramatically increased from 2.6 for neat PLA to $4.4 \mathrm{~kJ} / \mathrm{m}^{2}$ for PLA/PBAT (80:20) blend [8]. Compatibilizers are an important additive to enhance the compatibility of the blend. The blending of PLA/PBAT with compatibilizer is of significant interest since it could lead to the development of a new range of biodegradable polymeric materials with enhanced mechanical properties [9]. In one study, PLA/PBAT blend was applied in blown film extrusion in which a biodegradable polymer, poly(butylenesuccinate-co-adipate)(PBSA) was used as the compatibilizer [9]. The maximum tensile strength and impact strength of PLA/PBAT blend was achieved for the blend with $20 \mathrm{wt} . \%$ of PBAT. In another report by the same researchers, PLA/PBAT blends were prepared by using three different types of biopolymer as compatibilizers. They used a 70/30 ratio of PLA/PBAT blend and found maximum impact strength to be at $1 \%$ poly(hydroxybutylate-co-valerate) (PHBV) as compatibilizer [10].

Glycidyl methacrylate (GMA) grafted polymers are often used as reactive compatibilizers in polyester blends. The epoxy groups of GMA can react with carboxyl or hydroxyl groups of polyester and greatly increased the toughness without a severe loss of tensile strength [11].

Kumar et al. used GMA as a compatibilizer to prepare PLA/PBAT blend [12]. The optimum blend ratio of PLA/PBAT was found to be 75:25 with $51 \%$ improvement in impact strength by using 5\% GMA as a compatibilizer.

To meet industrial application requirements, further enhancement of mechanical and thermal properties of the polymer is required. One way of achieving it is by incorporation of nanofillers $[13,14]$. Polymer nanocomposites are a widely studied field of polymer technology. Nanocomposites are a group of composite material in which nanomaterials were used for reinforcing the matrix. Nanocomposites have been gaining increasing attention since the late 1990s as they offer an opportunity to explore new behaviors and functionalities beyond that 
of conventional materials. Many nanomaterials like carbon nanotube (CNT), graphene and nanoclay and so on have a unique set of properties such as extremely high strength and surface area. These make it an ideal material for reinforcing the polymer materials. Recently, many researchers focused on the application of graphene nanoplatelets (GNP) as nanofillers in the nanocomposite. GNP is a 2D nanomaterial which consists few layers of graphene. This can be synthesized by directly from graphite powder at very low cost. GNPs are not only low cost but also have high stiffness and thermal stability. Many previous studies have reported the effectiveness of GNP as an ideal reinforcing filler for biopolymer like PLA [3]. Chieng et al. studied the mechanical properties of PLA/epoxidized palm oil nanocomposites reinforced by GNP as novel filler [15]. The results showed that nanocomposites exhibited a $26.5 \%$ increment in tensile strength with $0.3 \%$ GNP loading.

The main objective of this study is to determine the effect of GNP content on mechanical and flammability properties of GMA compatibilized PLA/PBAT blends. There are very few reports available which explain the potential of GNP as a reinforcing and flame retardant filler. In this work, the graphene reinforced PLA/PBAT nanocomposites could find potential applications in automotive applications.

\section{EXPERIMENTAL}

\section{Materials}

Poly (lactic acid) (Nature Works TM PLA 3001D) in granules form was obtained from Nature Works LLC. It has a specific gravity of 1.24 and melts flow index $22 \mathrm{~g} / 10 \mathrm{~min}\left(230^{\circ} \mathrm{C} / 2.16 \mathrm{~kg}\right)$. Poly(butylene adipate-co-terephthalate) (PBAT, Ecoflex C1200) was purchased from Zhejiang Golden Suntown Chemical Limited in granules form with a density of $1.26 \mathrm{~kg} / \mathrm{m}^{3}$ and melt flow index of $3.8 \mathrm{~g} / 10 \mathrm{~min}\left(190{ }^{\circ} \mathrm{C} / 2.16\right.$ $\mathrm{kg}$ ). It is a biodegradable aliphatic-aromatic copolyester based on the monomers 1,4-butanediol, adipic acid and terephthalic acid in the polymer chain. Glycidyl methacrylate (GMA) was obtained from Dow Chemicals LTD. Graphene nanoplatelets (GNP), GNP-M-5 grade (99.5 $\%$ carbon), of average diameter $5 \mathrm{~mm}$ and an average thickness of less than $10 \mathrm{~nm}$ were purchased as a dry powder from XG Sciences (East Lansing, MI, USA).

\section{Blend Preparation}

The PLA and PBAT granules were separately dried overnight at 60 ${ }^{\circ} \mathrm{C}$ under vacuum before compounding to remove moisture. PLA/PBAT, PLA/PBAT/GMA and PLA/PBAT/GMA/GNP composites as listed in Table-1 were compounded in a twin screw extruder at $50 \mathrm{rpm}$ at $170-180{ }^{\circ} \mathrm{C}$ temperature range. The compounded materials were pelletized then injection molded at $180{ }^{\circ} \mathrm{C}$ into test specimens as per ASTM standard.

Table 1 Compounding formulations PLA/PBAT/GMA/GNP nanocomposites.

\begin{tabular}{|c|c|c|c|c|c|}
\hline Formulation & $\begin{array}{l}\text { PLA } \\
\text { (\%) }\end{array}$ & $\begin{array}{l}\text { PBAT } \\
(\%)\end{array}$ & $\begin{array}{l}\text { GMA } \\
\text { (phr) }\end{array}$ & $\begin{array}{l}\text { GNP } \\
\text { (phr) }\end{array}$ & Designation \\
\hline $\mathrm{F} 1$ & 75.00 & 25.00 & - & - & LA/PB \\
\hline $\mathrm{F} 2$ & 75.00 & 25.00 & 3 & - & LA/PB/3G \\
\hline F3 & 75.00 & 25.00 & 5 & - & $\mathrm{LA} / \mathrm{PB} / 5 \mathrm{G}$ \\
\hline F4 & 75.00 & 25.00 & 8 & - & LA/PB/8G \\
\hline F5 & 75.00 & 25.00 & 8 & 2 & $\begin{array}{l}\text { LA/PB/8G- } \\
2 \mathrm{GP}\end{array}$ \\
\hline F6 & 75.00 & 25.00 & 8 & 4 & $\begin{array}{l}\mathrm{LA} / \mathrm{PB} / 8 \mathrm{G}- \\
4 \mathrm{GP}\end{array}$ \\
\hline F7 & 75.00 & 25.00 & 8 & 6 & $\begin{array}{l}\mathrm{LA} / \mathrm{PB} / 8 \mathrm{G}- \\
6 \mathrm{GP}\end{array}$ \\
\hline
\end{tabular}

\section{Mechanical Properties}

The test specimen of blend nanocomposites were dried in vacuum at $50{ }^{\circ} \mathrm{C}$ and kept in sealed desiccators for 24 hours prior to testing. At least five specimens were subjected to mechanical testing for each formulation and their average was reported.

The Izod impact test was conducted according to ASTM D256 by using CEAST 9050 impact tester. For Izod impact test, the specimen's with the dimension of $64 \times 12.7 \times 3 \mathrm{~mm}$ a $\mathrm{V}$ notch angle of $45^{\circ}$ and a depth of $2.54 \mathrm{~mm}$ was made with CEAST AN50 notching machine.

The tensile modulus, tensile strength, and elongation at break of the nanocomposites blends were determined under ambient conditions according to ASTM D638. Tensile properties were conducted by using Universal Testing Machine with a crosshead speed of $5 \mathrm{~mm} / \mathrm{min}$.

\section{Thermogravimetric Analysis}

The thermal stability of polymer blends and nanocomposites were characterized using a thermogravimetric analyzer (Perkin-Elmer modal TGA 7). The 10-12 mg samples of polymer blends and nanocomposites were heated from room temperature to $600{ }^{\circ} \mathrm{C}$ at a heating rate of 20 ${ }^{\circ} \mathrm{C} / \mathrm{min}$ in the nitrogen atmosphere $(50 \mathrm{~mm} / \mathrm{min})$. Data on weight loss vs. temperature, final degradation temperature and percentage of residue were recorded.

\section{Fourier Transformation Infrared Spectroscopy}

To study the interaction between GMA/matrix and GNP/matrix ATR-FTIR spectroscopy (Perkin Elmer 1600 infrared spectrometer) was used. Analyses were done in a moisture free atmosphere at 32 scans with a resolution of $4 \mathrm{~cm}^{-1}$ and within the wave number range of 400 to $4000 \mathrm{~cm}^{-1}$.

\section{Morphology Analysis}

Dispersion of the GNP was observed using field emission scanning microscopy (FESEM). FESEM micrographs of the fractured surface of PLA/PBAT/GMA blend and PLA/PBAT/GMA/GNP nanocomposites were obtained by using JEOL JSM 7600F. The samples were platinum coated for avoiding charging by using JFC 1600 coater.

\section{X-ray Diffraction}

X-ray diffraction patterns were collected using X-ray diffractometer (modal Bruker D8 and Ni-filtered $\mathrm{Cu} \mathrm{K} \alpha$ radiation) at an angular incidence of $10^{\circ}-80^{\circ}$. XRD scan of the GNP powder along with the composites samples was collected at $40 \mathrm{kV}$ and $50 \mathrm{~mA}$ with scan rate $5 \% \mathrm{~min}$.

\section{Limiting Oxygen Index}

The minimum concentration of oxygen in which a polymer sample burn over a distance of $50 \mathrm{~mm}$ or burn for three minutes is known as limiting oxygen index. The high value of LOI shows low flammability of the material. Specimen dimension for the test is $125 \times 10 \times 4 \mathrm{~mm}$. This test was carried out according to ASTM D2863.

\section{UL-94 Test}

According to UL-94 flammability test, PLA/PBAT blend, GMA compatibilized blend and GNP reinforced nanocomposites with the dimensions of $127 \times 12 \times 3 \mathrm{~mm}$ were subjected to a vertical rate of burning. The rate of burning was determined from the average of three samples for each test. The char was collected after the test.

\section{RESULTS AND DISCUSSION}

\section{Mechanical Properties}

In this study all PLA/PBAT blends were prepared at a fixed ratio of 75:25 w/w respectively, based on the optimum composition determined by Kumar et al. [12]. Then the varying amount of GMA as a reactive compatibilizer was added in PLA/PBAT blends. The Izod impact test was carried out to evaluate the toughness of PLA/PBAT and PLA/PBAT blends with different GMA content and the results are shown in Figure 1. It reveals that impact strength of blends increased from 47.1 for the uncompatibilized blend to 72.1 and $84 \mathrm{~J} / \mathrm{m}$, respectively for 3 and 5 phr GMA content blend. This could be due to the improved interfacial adhesion between PLA and PBAT in the presence of GMA compatibilizer. A similar trend was reported by Teamsinsungvon et al. where they compatibilized PLA/PBAT blend by 
PLA-graft-maleic anhydride (PLA-g-MA) [16]. With a further increase to $8 \mathrm{phr}$ GMA, an enormous increase in impact strength was observed. This remarkable enhancement in the impact strength is due to the toughening effect of the compatibilizer that has caused a brittle-ductile transition in the PLA/PBAT system [17]. GMA can also act as a reactive compatibilizer due to the presence of epoxy groups which may react with the hydroxyl and carboxyl groups in the PLA and PBAT. This occurs due to reactions involving the epoxy group ring opening and the creation of covalent bonds with hydroxyl formation [18]. A random terpolymer of ethylene acrylic ester (T-GMA) was formed as shown in Figure 2, whereby TGMA reacted with PLA and PBAT to form an ester linkage which can be connected to both polymers. Due to the significant enhancement of PLA/PBAT with $8 \mathrm{phr}$, the formulation was selected for further investigation.

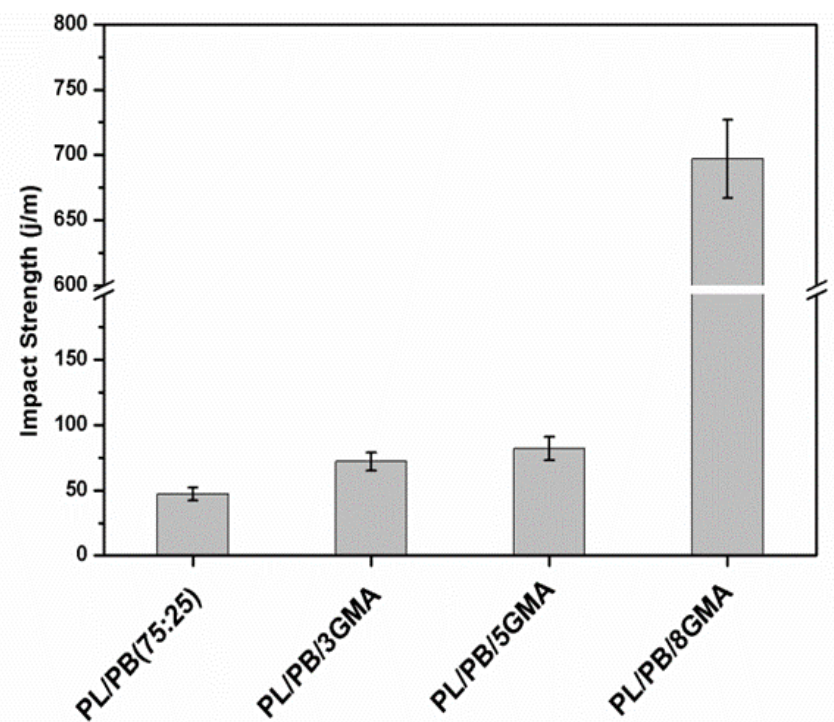

Fig. 1 Effect of GMA content on impact strength of PLA/PBAT blend.

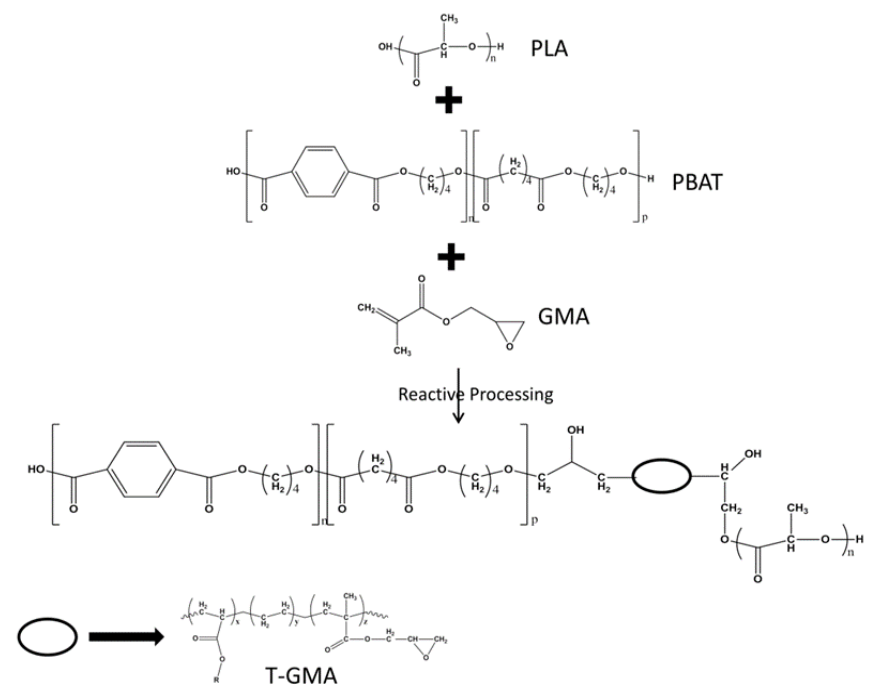

Fig. 2 Predicted reaction between PLA, PBAT, and GMA.

The tensile properties of PLA/PBAT blend prepared at a ratio of 75:25 with GMA at various contents are represented in Figure 3. GMA at various contents was added to enhance the interfacial compatibility of PLA/PBAT blend. However, from Figure $3 \mathrm{a}$ it can be observed that with an increase in GMA content, the tensile modulus and tensile strength of PLA/PBAT blends decreased. As the incorporation of 3, 5 and 8 phr GMA into PLA/PBAT blends, the tensile modulus reduced by $3.6,7.2$ and $28.6 \%$ respectively, while the tensile strength decreased by $7.7,7.5$ and $44.1 \%$ respectively, compared with un-compatibilized PLA/PBAT blend. The elongation at break (shown in Figure 3b) increased consistently with the addition of GMA and a remarkable improvement of the elongation at break was observed at 8 phr GMA content, which was associated with the elastomeric nature of PBAT.

It is observed from the result that impact strength of PLA/PBAT blends increased with increase in GMA content with a concomitant decrease in tensile strength. The results show, for PLA/PBAT blend with 8 phr GMA content the impact strength is highest but tensile strength and modulus was lowest. In order to improve the tensile strength and modulus without affecting the impact strength, GNPs was incorporated as fillers to PLA/PBAT/8GMA blend. Figure 4a shows the influence of different GNP contents on tensile strength and tensile modulus of PLA/PBAT/8GMA blend nanocomposites. The effect of GNP content on the tensile modulus and tensile strength of compatibilized blends showed a steadily increasing trend compared to the blend without GNP (as shown in Figure 4a). The tensile modulus increased from $636 \mathrm{MPa}$ to $1039 \mathrm{MPa}$ at 0 to $6 \mathrm{phr}$ GNP content (i.e., about $63 \%$ increment). These observations are attributed to high stiffness of GNP that reinforce into the blend matrix. The increase in tensile modulus is also due to high dispersion of GNP as evidenced by morphological studies shown in Figure 6.
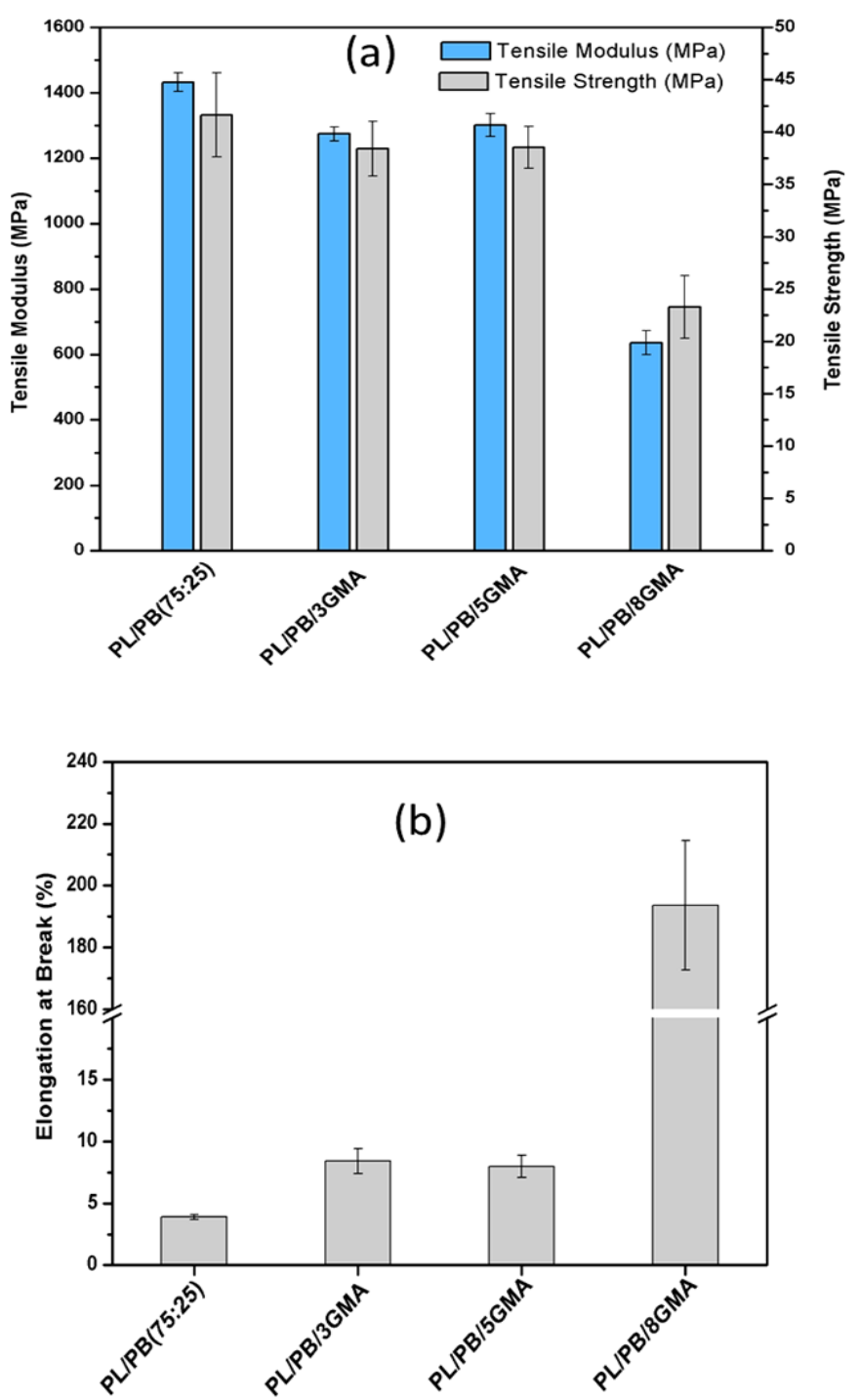

Fig. 3 The comparison of (a) The tensile modulus and tensile strength (b) elongation at break of PLA/PBAT blend and PLA/PBAT blend with different GMA content.

However, the percentage of elongation at break decreased with the addition of GNP as shown in Figure 4b. A significant drop in elongation at break was observed at 2 phr GNP content which is attributed to the high stiffness of GNP that compensated the elastomeric property of compatibilized PLA/PBAT blend. The elongation at break further decreased consistently with the increase in GNP content to 4 phr and 6 phr. 

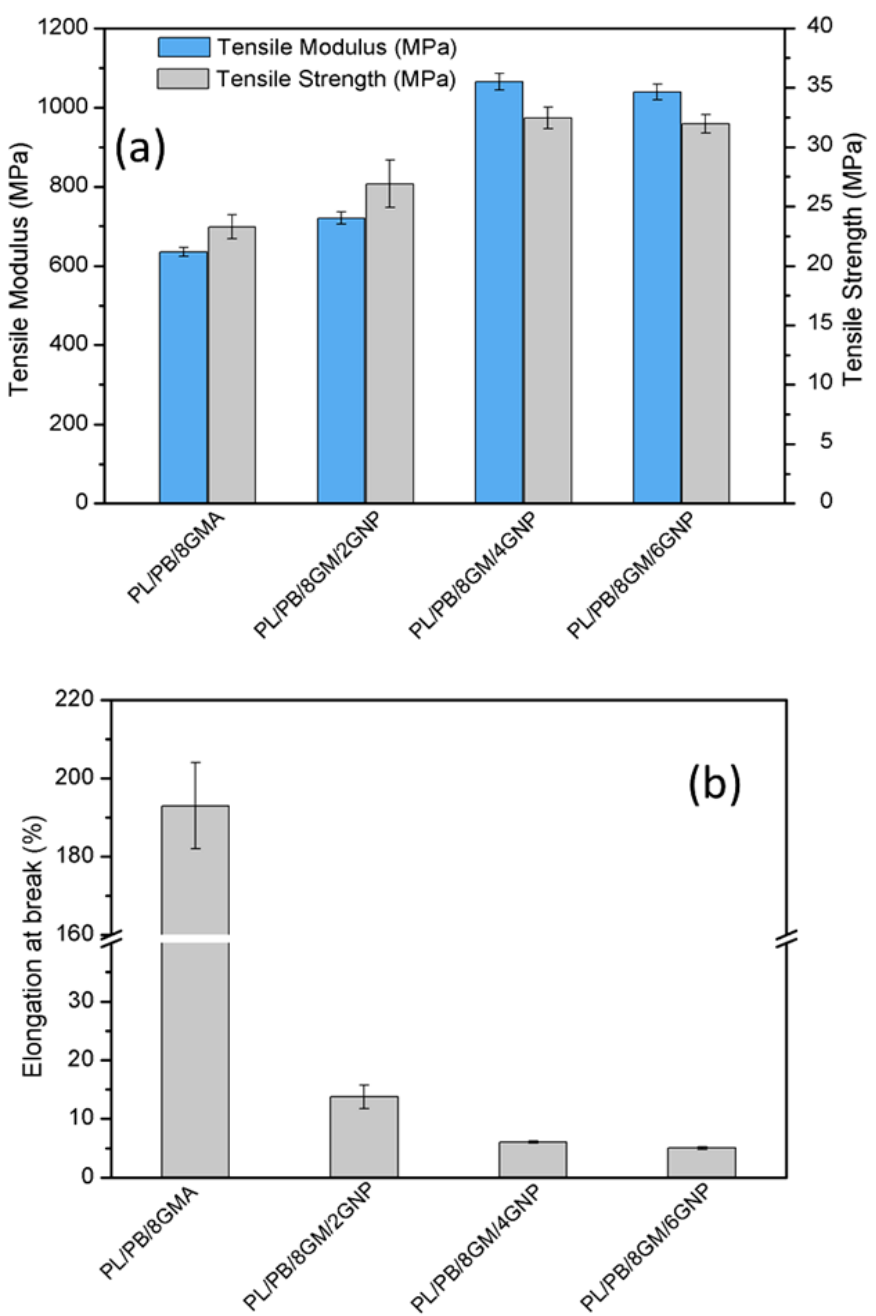

Fig. 4 The effect on (a) The tensile modulus and tensile strength (b) elongation at break of, LA/PB/8G blend and its nanocomposites with GNP contents.

Figure 5 shows the effect of GNP contents on impact strength of GMA compatibilized blends. It was observed that impact strength decreased sharply from $697 \mathrm{~J} / \mathrm{m}$ to $132.6 \mathrm{~J} / \mathrm{m}$ with the incorporation of $2 \mathrm{phr}$ GNP. The impact strength of GMA compatibilized blends decreased further to $54.2 \mathrm{~J} / \mathrm{m}$ and $46.3 \mathrm{~J} / \mathrm{m}$ with higher GNP contents, $4 \mathrm{phr}$, and $6 \mathrm{phr}$ respectively. The decreased trend behavior is mainly due to incompatibility between the matrix and filler and also the heterogeneous nature of GNP nanocomposites [19]. The addition of GNP increased the brittleness in the GMA compatibilized blends and thus resulted in a reduction of impact strength.

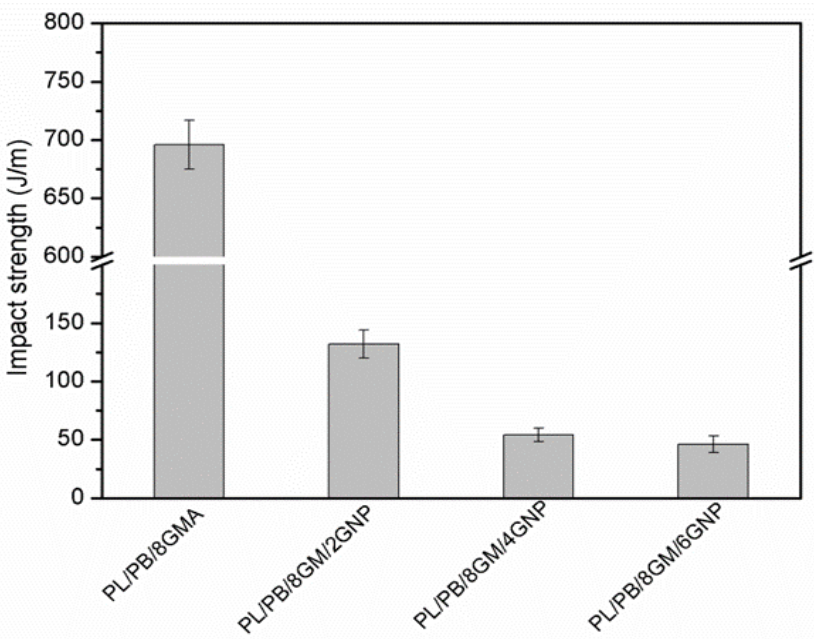

Fig. 5 Effect of GNP content on impact strength of LA/PB/8G blends.

\section{Morphological analysis}

Morphology of the blend shows the dispersion level and interaction between polymer and nanofiller. Figure 6 (a-e) shows the FESEM micrographs of the impact fracture surface of PLA/PBAT blend, $8 \mathrm{phr}$ GMA compatibilized blend and variation of GNP content PLA/PBAT blend. Figure 6 ( $a$ and $b$ ) represent the PLA/PBAT blend without GMA and with 8phr GMA, respectively. It is evident from Figure 6a that without GMA, PLA/PBAT shows an immiscible two-phase structure with PBAT phases distributed and dispersed uniformly in the PLA matrix. As compared to PLA/PBAT blend the PLA/PBAT 8phr GMA (Figure $6 \mathrm{~b}$ ) blend shows better miscibility and more shear yielding when it was fractured. The micrographs of impact fractured surface of this blend show a ductile fracture.

Figure 6 (c-e) shows the impact fractured surface nanocomposites for 2, 4 and 6 phr GNP respectively. The GNPs are distributed evenly in the matrix which might be contributing to the enhanced tensile strength of the GNP reinforced nanocomposites. From the Figure 6 (ce), it can easily be seen that GNP is pulled out and projected over the fractured surfaces. It is a clear indication of lack of interaction between filler and matrix. A deep analysis of Figure 6(c-e) it can be observed that a small gap between GNP and polymer matrix is present (shown by arrows), which is due to the absence of physical or chemical bonding between nanoparticles and polymer. Morphology study suggests, that even though GNP have good distribution all over the matrix but the absence of bonding between GNP and matrix polymer have resulted in below expected mechanical properties. The lack of interaction could be because to either of the two possible reasons, firstly less dispersion and individualization of GNP and secondly no interaction between GNP and polymer matrix. To investigate the dispersion level of GNP, XRD was carried out.
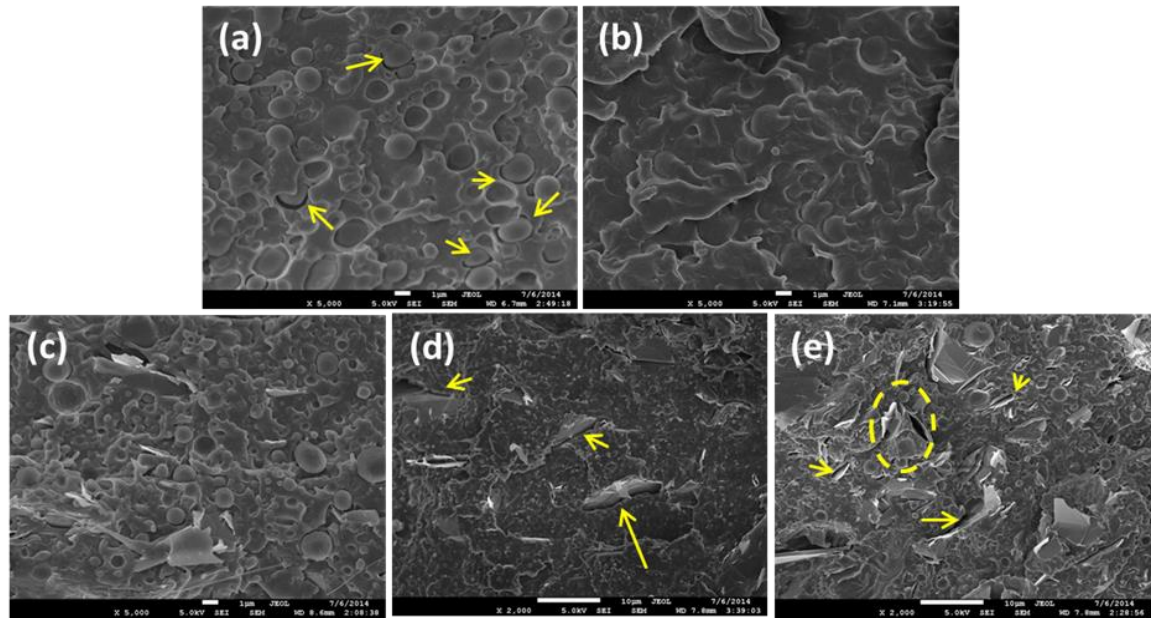

Fig. 6 SEM images of PLA/PBAT blend at 5.0kX (a) LA/PB (b) LA/PB/8G and at 2.0kX (c) LA/PB/8G-2GP (d) LA/PB/8G-4GP (e) LA/PB/8G-6GP nanocomposites. 


\section{X-ray Diffraction}

The X-ray diffractogram of GNP powder, PLA/PBAT blend, GMA compatibilized blend and GNP reinforced nanocomposites are shown in Figure 7. A broad amorphous peak from the PLA/PBAT blend was observed at around $17.5^{\circ}$. This confirms the PLA/PBAT has an amorphous microstructure. In the case of graphene powder, the spectrum showed a sharp intense peak at $2 \theta=26.5^{\circ}(\mathrm{d}=3.37 \AA)$ and a small diffraction peak at $54.6^{\circ}(\mathrm{d}=1.68 \AA)$ which confirm the crystallinity of GNP.

The diffraction pattern for GMA compatibilized blend shows a small peak at $2 \theta=16.5^{\circ}(\mathrm{d}=5.36 \AA)$ which could presumably be attributed to the formation of random terpolymer due to the reaction of GMA and PLA/PBAT blend. This assertion was predicted by Kumar et al., [12]. However, this peak which was assigned to the formation of random terpolymer decreased with increasing GNP content due to the heterogeneous nucleation effect of the GNP. The characteristic GNP peak remains visible in all nanocomposites formulations which show that the occurrence of exfoliation of the GNP in the matrix did not occur. This might be the plausible reason for the marginal increase in the tensile properties as discussed earlier.

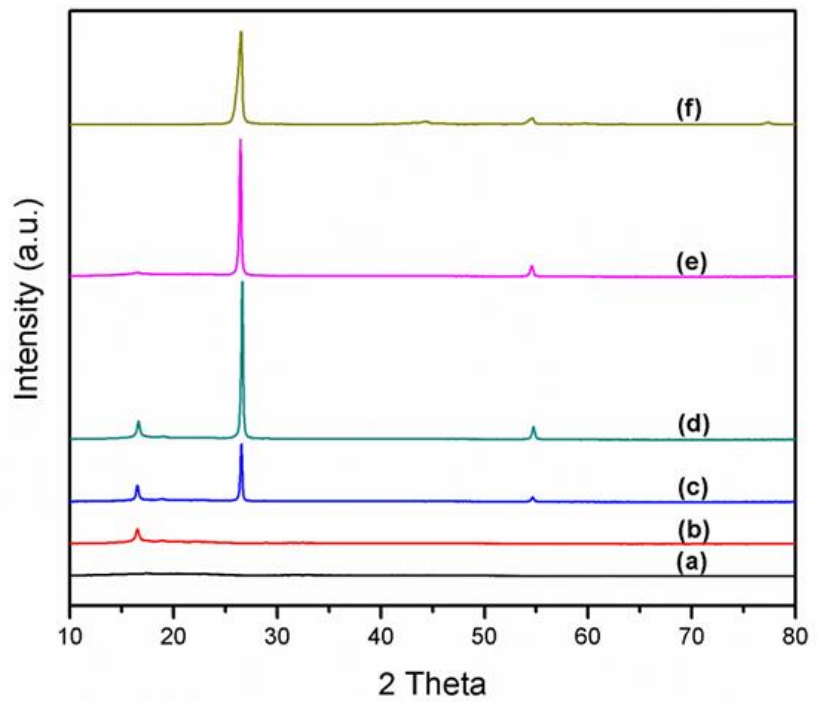

Fig. 7 X-ray diffractogram of the (a) LA/PB (b) LA/PB/8G (c) LA/PB/8G2GP (d) LA/PB/8G-4GP (e) LA/PB/8G-6GP (f) GNP powder.

\section{Fourier Transform Infrared Spectroscopy (FTIR)}

The chemical interaction between GNP and polymer was evaluated by FTIR analysis. Figure 8 shows the FTIR spectra of GNP powder, 8phr GMA compatibilized blend and GNP reinforced PLA/GNP nanocomposites. It can be seen that no visible peaks were observed in the spectrum of GNP powder because GNP can absorb almost all IR spectrum which is tested in this study. Geng et al. prepared GNP from natural graphite flakes and find similar FTIR pattern in their study for GNPs [20]. Moreover, the results confirming the purity of graphene sheets used in this study as there are no graphite oxide peaks in the GNP powder [21,22]. The characteristic peaks of graphite oxide appeared at $3400 \mathrm{~cm}^{-1}$ (O-H stretching vibration), $1720 \mathrm{~cm}^{-1}(\mathrm{C}=\mathrm{O}$ stretching vibration), $1220 \mathrm{~cm}^{-1}$ (C-OH stretching), and $1060 \mathrm{~cm}^{-1}$ (C-O stretching) [19].

In the case of GMA compatibilized blend, it can be seen that the peak at $1750 \mathrm{~cm}^{-1}$ which was due to the carbonyl stretching $(\mathrm{C}=\mathrm{O})$ in the ester linkage. According to Kumar et al. [12], the bending peak of substituted benzene was located at $872 \mathrm{~cm}^{-1}$ in both GMA compatibilized blend and GNP reinforced nanocomposites. In the case of the GMA compatibilized blend, peaks at $814 \mathrm{~cm}^{-1}$ and $910 \mathrm{~cm}^{-1}$ representing epoxide group of GMA. Also, very broad hydroxyl (-OH) band of the ring opening reaction of the epoxide group in GMA near $3600 \mathrm{~cm}^{-1}$ was observed [23].

In the presence of GMA in the PLA/PBAT blend, the pattern of decomposition also showed a two-step process. Evidence from DTG curves showed that with the presence of GMA, both peaks came closer to each other compared with PLA/PBAT blend. This indicated that there was an improvement in compatibility between PLA and PBAT. As suggested by Kumar et al [12] this could be due to dehydration from the hydroxyl group of PLA and carboxylic group of PBAT units and thermal cleavage of ester linkage by hydrolysis and scission of $\mathrm{C}-\mathrm{O}$ and $\mathrm{C}-\mathrm{C}$ bonds [12].

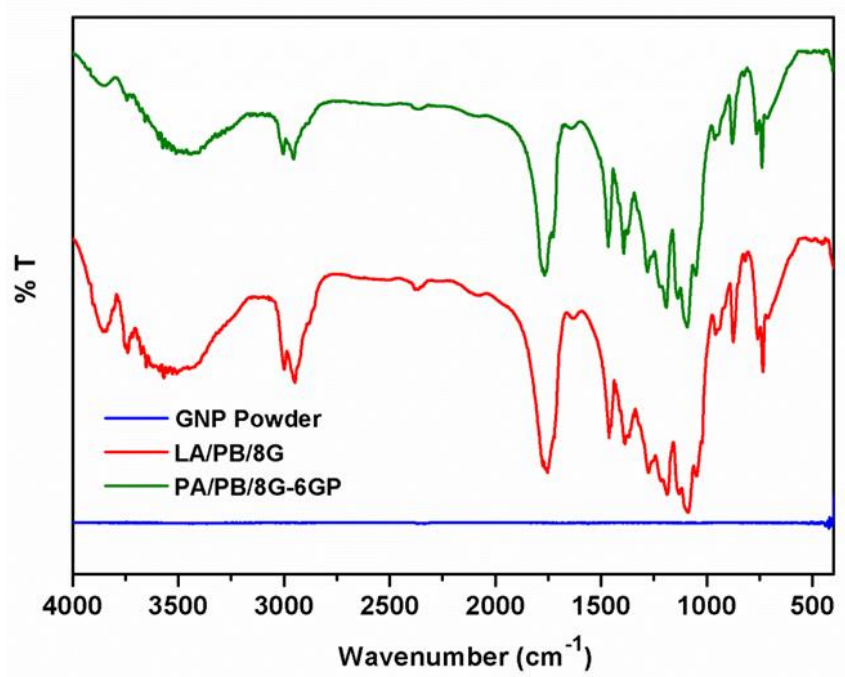

Fig. 8 FTIR spectra of GNP powder, LA/PB/8G and LA/PB/8G-6GP.

Overall, it was observed that there is no significant change in peaks position of GNP reinforced nanocomposites which indicate that there was no chemical interaction occurred between GNP and the blend matrix. Hence, it is suggested that only the physical interaction possible between GNP and the polymer matrix. A similar observation was made by Inuwa et al. in their study on GNP reinforced polyethylene terephthalate/polypropylene nanocomposites [19].

\section{Thermogravimetric Analysis}

The TGA thermograms of PLA, PLA/PBAT blend, PLA/PBAT blend with a variation of GMA and the blend nanocomposites are represented in Table 2 and Figures 9 and 10. It was observed that the thermal degradation of virgin PLA started at $340^{\circ} \mathrm{C}$ and the maximum decomposition temperature was noticed at $367.8^{\circ} \mathrm{C}$ as shown in Table 2. Based on the derivative thermogram (DTG), in virgin PLA, a single step decomposition process was observed whereas PLA/PBAT blend demonstrated two steps decomposition.

Table 2 : Degradation temperature of PLA, PLA/PBAT blend, GMA compatibilized blends and GNP nanocomposites.

\begin{tabular}{lllll}
\hline Sample & $\mathbf{T}_{10}\left({ }^{\circ} \mathbf{C}\right)$ & $\mathbf{T}_{50}\left({ }^{\circ} \mathbf{C}\right)$ & $\mathbf{T}_{\max }\left({ }^{\circ} \mathbf{C}\right)$ & Char (\%) \\
\hline LA & 340.0 & 361.7 & 367.8 & 0.0 \\
LA/PB & 331.8 & 361.5 & 362.1 & 1.3 \\
LA/PB/3G & 319.7 & 360.8 & 363.0 & 1.5 \\
LA/PB/5G & 306.7 & 355.6 & 359.2 & 1.6 \\
LA/PB/8G & 309.7 & 357.8 & 362.6 & 1.6 \\
LA/PB/8G-2GP & 321.5 & 358.2 & 360.4 & 1.3 \\
LA/PB/8G-4GP & 335.7 & 364.1 & 363.7 & 5.0 \\
LA/PB/8G-6GP & 339.6 & 367.1 & 364.9 & 5.6 \\
\hline
\end{tabular}

$\mathrm{T}_{10}: 10 \%$ weight loss decomposition temperature considered as initial decomposition temperature; $\mathrm{T}_{50}$ : $50 \%$ weight loss decomposition temperature; Tmax: maximum decomposition temperature.

It shows that the initial thermal degradation of $8 \mathrm{phr}$ GMA in PLA/PBAT blend was about $15{ }^{\circ} \mathrm{C}$ lower than PLA/PBAT blend with char residue of $1.59 \%$. Similarly, GNP nanocomposites also exhibit two steps decomposition process. The thermal stability of GNP reinforced GMA compatibilized blend increased with increasing GNP 
content as indicated by the $\mathrm{T}_{10}$ and $\mathrm{T}_{\max }$ values. The thermal stability enhancement was attributed due to the high aspect ratio and higher thermal stability of GNP which acts as a barrier and prevented the emission of gaseous molecules during thermal degradation [19, 24]. It was seen that the char residue increased significantly when the GNP content was increased from 2 to 4 phr content.
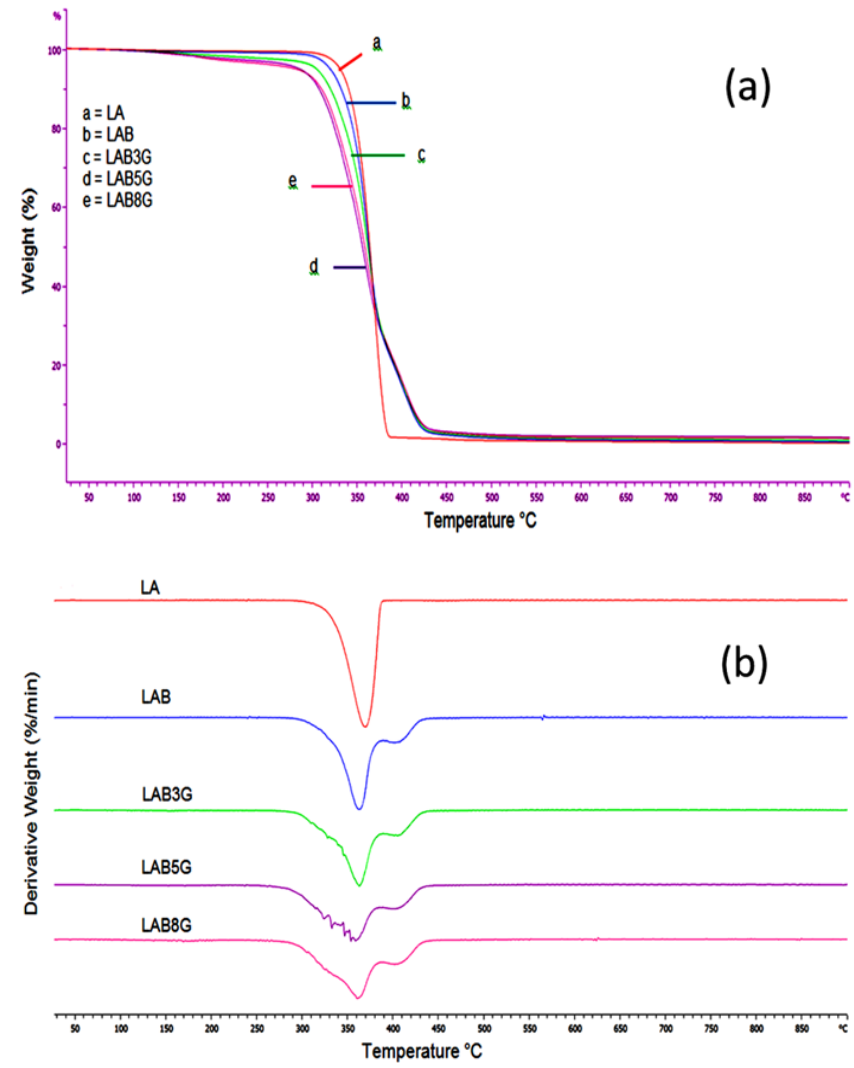

Fig 9 TGA (a) and DTG (b) of LA, LA/PB, LA/PB/3G, LA/PB/5G, $\mathrm{LA} / \mathrm{PB} / 8 \mathrm{G}$
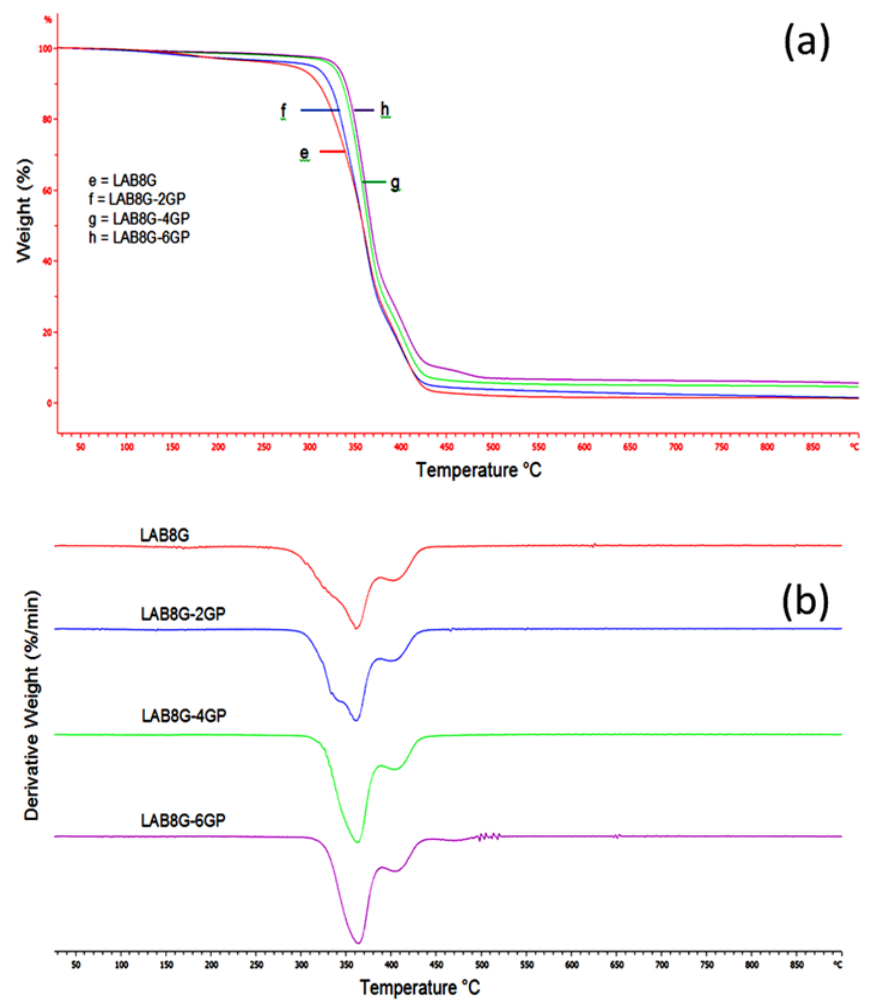

Fig. 10 TGA (a) and DTG (b) of LA/PB/8G, LA/PB/8G-2GP, LA/PB/8G4GP, LA/PB/8G-6GP.

\section{Flammability}

LOI and UL-94 test were done to observe the effects of compatibilizer and GNP in the PLA/PBAT blend and nanocomposites respectively. Table 3 reports the results of LOI and UL-94 test of PLA/PBAT blend, GMA compatibilized blends and GNP reinforced blend nanocomposites. The PLA/PBAT blend without GMA shows the highest LOI value of $24 \%$ and classified as V-2 ranking due to the burning drops has ignited the cotton. Incorporation of 3, 5 and $8 \mathrm{phr}$ GMA compatibilizer into PLA/PBAT blend reduced the LOI values but the UL-94 test remained same which is V-2 rating. For PLA/PBAT containing 3 and 6 phr GMA, lower drips were observed and for a sample containing $8 \mathrm{phr}$ GMA, moderate drips were observed. This could be due to the decreased in melt viscosity of the blend with a high content of compatibilizer that caused the material to drip slower.

Table 3: LOI and UL-94 ratings PLA/PBAT blend, GMA compatibilized blends and GNP nanocomposites.

\begin{tabular}{llll} 
Sample & LOI \% & \multicolumn{2}{l}{ UL-94 Ratings } \\
\hline LA/PB & 24 & V-2 & Moderate dripping \\
LA/PB/3G & 23 & V-2 & Low dripping \\
LA/PB/5G & 22 & V-2 & Low dripping \\
LA/PB/8G & 21 & V-2 & Moderate dripping \\
LA/PB/8G-2GP & 20 & V-2 & Low dripping \\
LA/PB/8G-4GP & 21 & V-0 & No dripping \\
LA/PB/8G-6GP & 22 & V-0 & No dripping \\
\hline
\end{tabular}

Nanocomposite sample of PLA/PBAT/8GMA with 2 phr GNP shows the lowest LOI value among all the samples. However, the addition of 4 and 6 phr GNP in 8 phr GMA compatibilized blends showed a positive effect on both LOI values and UL-94 rating. The UL94 test of 4 and 6 phr GNP containing nanocomposite showed no dripping thus improving the rating from $\mathrm{V}-2$ to $\mathrm{V}-0$. The higher amount of GNP increased melt viscosity of the nanocomposites preventing the material from dripping. Besides that, the higher content of GNP also produced char that prevented the materials from burning and dripping. This observation can be correlated to the higher thermal stability observed in TGA analysis.

\section{CONCLUSION}

The effects of GMA as a compatibilizer and GNP as a reinforcement in PLA/PBAT blends and nanocomposites respectively have been investigated. The main conclusions that can be derived are as follows:

1. The incorporation of $8 \mathrm{phr}$ GMA into PLA/PBAT (75/25) blend as a compatibilizer resulted in a significant increase in impact strength (more than 14 times higher) compared to the uncompatibilized PLA/PBAT nanocomposites.

2. Young's modulus and tensile strength of compatibilized PLA/PBAT nanocomposites increased upon addition of GNP and reached maximum values at $4 \mathrm{phr}$ before decreasing slightly. However, the impact strength of the nanocomposite was observed to decrease. The improvement of the stiffness and tensile strength were attributed to high stiffness and reasonable dispersion of GNP in the blend matrix as observed using FESEM.

3. The thermal stability and the flame retardancy of the GNP reinforced blend nanocomposite were also improved with an increase in the GNP content. Interestingly, the nanocomposite sample showed a UL-94 rating of V0 at 4 and $6 \mathrm{phr}$ of GNP. TGA results also showed that GNPs have enhanced the thermal stability of GMA compatibilized blend as indicated by the increase in $\mathrm{T}_{10}, \mathrm{~T}_{\max }$ and char residue. 
4. FTIR spectroscopy did not show any significant changes in peak positions of GNP reinforced blend nanocomposites compared to GMA compatibilized blends. This reveals that no chemical interaction between GNP and the blend matrix occurred.

\section{REFERENCES}

[1] J. Tengsuthiwat, U. Asawapirom, S. Siengchin and J. Karger-Kocsis, Mechanical, thermal, and water absorption properties of melamineformaldehyde-treated sisal fiber containing poly (lactic acid) composites, Journal of Applied Polymer Science 135 (2) (2018) 45681.

[2] R. Nehra, S. N. Maiti and J. Jacob, Analytical interpretations of static and dynamic mechanical properties of thermoplastic elastomer toughened PLA blends, Journal of Applied Polymer Science 135 (1) (2018) 1-13.

[3] H. Balakrishnan, I. Masoumi, A. A. Yussuf, M. Imran, A. Hassan and M.U. Wahit, Ethylene Copolymer Toughened Polylactic Acid Nanocomposites, Polymer-Plastics Technology and Engineering 51 (1) (2012) 19-27.

[4] P. Liewchirakorn, D. Aht-Ong and W. Chinsirikul, Practical Approach in Developing Desirable Peel-Seal and Clear Lidding Films Based on Poly(Lactic Acid) and Poly(Butylene Adipate-Co-Terephthalate) Blends, Packaging Technology and Science 31 (5) (2018) 296-309.

[5] O. Çoban, M. Ö. Bora, T. Kutluk and G. Özkoç, Mechanical and thermal properties of volcanic particle filled PLA/PBAT composites, Polymer Composites 39 (S3) (2018) E1500-E1511.

[6] K. Fukushima, M.-H. Wu, S. Bocchini, A. Rasyida and M.-C. Yang, PBAT based nanocomposites for medical and industrial applications, Materials Science and Engineering: C 32 (6) (2012): 1331-1351.

[7] E. Quero, A. J. Müller, F. Signori, M. B. Coltelli and S. Bronco, Isotherma Cold-Crystallization of PLA/PBAT Blends With and Without the Addition of Acetyl Tributyl Citrate, Macromolecular Chemistry and Physics 213, (1) (2012) 36-48.

[8] L. Jiang, M. P. Wolcott and J. Zhang, Study of Biodegradable Polylactide/Poly(butylene adipate-co-terephthalate) Blends, Biomacromolecules 7 (1) (2006) 199-207.

[9] W. Pivsa-Art, S. Pavasupree, O. Narongchai, U. Insuan, P. Jailak and S. Pivsa-Art, Preparation of Polymer Blends Between Poly (L-Lactic Acid), Poly (Butylene Succinate-Co-Adipate) and Poly (Butylene Adipate-CoTerephthalate) for Blow Film Industrial Application, Energy Procedia 9 (2011) 581-588.

[10] W. Pivsa-Art, A. Chaiyasat, S. Pivsa-Art, H. Yamane and H. Ohara Preparation of Polymer Blends between Poly(Lactic Acid) and Poly(Butylene adipate-co-terephthalate) and Biodegradable Polymers as Compatibilizers, Energy Procedia 34 (2013) 549-554.

[11] N. Zhang, Q. Wang, J. Ren and L. Wang, Preparation and properties of biodegradable poly(lactic acid)/poly(butylene adipate-co-terephthalate) blend with glycidyl methacrylate as reactive processing agent, Journal of Materials Science 44 (1) (2009) 250-256.

[12] M. Kumar, S. Mohanty, S. Nayak and M. R. Parvaiz, Effect of glycidyl methacrylate (GMA) on the thermal, mechanical and morphological property of biodegradable PLA/PBAT blend and its nanocomposites, Bioresource Technology 101 (21) (2010) 8406-8415.

[13] S. Adrar, A. Habi, A. Ajji and Y. Grohens, Synergistic effects in epoxy functionalized graphene and modified organo-montmorillonite PLA/PBAT blends, Applied Clay Science 157 (2018): 65-75.

[14] S. Zhou, A. N. Hrymak and M. R. Kamal, Properties of microinjectionmolded multi-walled carbon nanotubes-filled poly(lactic acid)/poly[(butylene succinate)-co-adipate] blend nanocomposites, Journal of Materials Science 53 (12) (2018) 9013-9025.

[15] B. W. Chieng, N. A. Ibrahim, W. M. Z. Wan Yunus, M. Z. Hussein and V. Silverajah, Graphene Nanoplatelets as Novel Reinforcement Filler in Poly(lactic acid)/Epoxidized Palm Oil Green Nanocomposites: Mechanical Properties, International Journal of Molecular Sciences 13 (9) (2012) 10920-10934

[16] A. Teamsinsungvon, Y. Ruksakulpiwat and K. Jarukumjorn. Paper presented at 18th International Conference on Composite Materials (ICCM18), Korea, 21-26 ${ }^{\text {th }}$ August (2011).

[17] S. Lin, W. Guo, C. Chen, J. Ma, and B. Wang, Mechanical properties and morphology of biodegradable poly(lactic acid)/poly(butylene adipate-coterephthalate) blends compatibilized by transesterification, Materials \& Design (1980-2015) 36 (2012) 604-608.

[18] Y. Corre, J. Duchet, J. Reignier, A. Maazouz, Melt strengthening of poly (lactic acid) through reactive extrusion with epoxy-functionalized chains Rheologica Acta 50 (7) (2011) 613-629.

[19] I. M. Inuwa, A. Hassan, S. A. Samsudin, M. Kassim, M. Haafiz and M. Jawaid, Mechanical and thermal properties of exfoliated graphite nanoplatelets reinforced polyethylene terephthalate/polypropylene composites, Polymer Composites 35 (10) (2014) 2029-2035.

[20] Y. Geng, S. J. Wang, and J.-K. Kim, Preparation of graphite nanoplatelets and graphene sheets, Journal of Colloid and Interface Science 336 (2) (2009) 592-598.

[21] Z. Xu and C. Gao, In situ Polymerization Approach to GrapheneReinforced Nylon-6 Composites, Macromolecules 43 (16) (2010) 67166723.

[22] T. Kuila, S. Bose, C. E. Hong, M. E. Uddin, P. Khanra, N. H. Kim and J. H. Lee, Preparation of functionalized graphene/linear low density polyethylene composites by a solution mixing method, Carbon 49 (3) (2011) 1033-1037

[23] J. M. Jin, J. M. Lee, M. H. Ha, K. Lee and S. Choe, Highly crosslinked poly(glycidyl methacrylate-co-divinyl benzene) particles by precipitation polymerization, Polymer 48 (11) (2007) 3107-3115.

[24] M. J. Osman, N. A. Ibrahim, and W. M. Z. W. Yunus, Effect of Modified Clay on the Morphological and Thermal Properties of PLA/PBAT Nanocomposites, Oriental Journal of Chemistry 33 (6) (2017) 3015-3023. 